\title{
Impact of Demographic Factors, Obesity, and Oral Health Status on Self-esteem among School-going Children in United Arab Emirates: A Cross-sectional Study
}

\author{
Foroogh Abdalla Khadri', Vellore K. Gopinath ${ }^{2}$, Mark P. Hector ${ }^{3}$, Elizabeth S. Davenport ${ }^{4}$
}

${ }^{1}$ Department of Paediatric Dentistry, Sharjah Specialised Dental Centre, Ministry of Health \& Prevention, ${ }^{2}$ Department of Preventive and Restorative Dentistry, College of Dental Medicine, University of Sharjah, Sharjah, UAE, ${ }^{3}$ School of Dentistry, University of Dundee, Dundee, ${ }^{4}$ Center of Oral Growth and Development (Paediatric Dentistry), Barts and The London School of Medicine and Dentistry, London, UK

Received : 13-10-19. Revised : $21-02-20$ Accepted : 06-03-20. Published : 27-04-20.
Objectives: The objective of this study was to determine if oral health, obesity, and demographic factors have an impact on self-esteem among school-going children in United Arab Emirates. Materials and Methods: Ten schools (six private and four public) were selected using random digit table. Decayed, missing, and filled teeth index according to the World Health Organization criteria was used to assess dental caries. Obesity was measured by body mass index (BMI = weight $[\mathrm{kg}] /$ height $\left[\mathrm{m}^{2}\right]$ ). Data related to demographic details and toothbrushing were collected and entered into assessment forms. The mental well-being was assessed using Rosenberg Self-esteem Scale. Results: Self-esteem score was 19.8 (standard deviation $[\mathrm{SD}], \pm 3.8)$ mean, and ranged from 19.1 to 20.5 . The presence or absence of dental caries or their body shape (obesity/overweight/normal weight) had no impact on the self-esteem scores. Of the participants, $93 \%$ brushed daily, whereas the brushing frequency was significantly greater in female children $(98 \%)(P<0.001)$ and children with higher self-esteem scores $(P=0.066)$. The self-esteem scores of school children was positively associated with age as elder children had higher scores $(P=0.001)$. Children of Indian origin had lower self-esteem $(P=0.004)$. BMI was negatively associated $(P=0.006)$. Conclusion: Rosenberg Self-esteem Scale scores were found to be lower in young children and Indian children. The child's obesity and dental caries status had no significant influence on their self-esteem. High self-esteem in older children can be linked with increased toothbrushing frequency.

KeYwords: Dental caries, obesity, self-esteem, toothbrushing

\section{INTRODUCTION}

elf-esteem is defined as a person's self-confidence $\checkmark$ and value. In 1965, self-esteem was first measured and defined by Rosenberg to evaluate psychological well-being by Rosenberg Self-esteem Scale, ${ }^{[1]}$ which is mostly used among adolescents. Rosenberg Scale has been translated in many languages ${ }^{[2-4]}$ and has been used in country around the world. Previous studies have linked self-esteem to individual's mental wellbeing, smoking and alcohol consumption, ${ }^{[5]}$ physical activity, ${ }^{[6,7]}$ toothbrushing, ${ }^{[8,9]}$ and obesity ${ }^{[7,10-13]}$

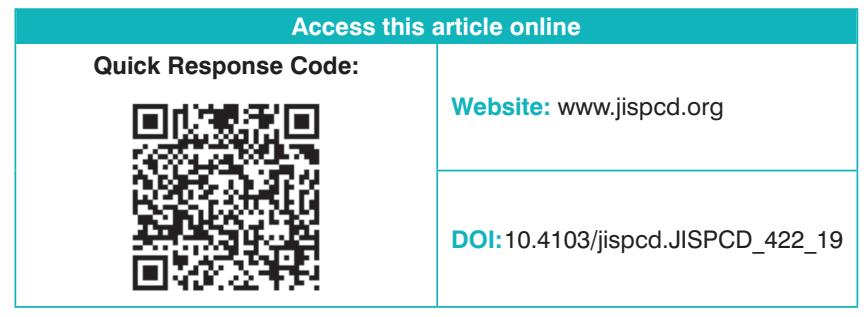

Published research has shown the adverse effect of obesity and overweight on physical and psychological health. ${ }^{[14]}$ This concept has been further reinforced by various research investigators associating obesity and mental health, ${ }^{[15]}$ which include depression, ${ }^{[16]}$ healthrelated quality of life (HRQOL), ${ }^{[15,17]}$ socialization, ${ }^{[18]}$ body image ${ }^{[19]}$ and loneliness, sadness, nervousness, and

Address for correspondence: Dr. Vellore Kannan Gopinath, Department of Preventive and Restorative Dentistry, College of Dental Medicine, University of Sharjah, Sharjah, UAE. E-mail: gopinathvk@yahoo.com

This is an open access journal, and articles are distributed under the terms of the Creative Commons Attribution-NonCommercial-ShareAlike 4.0 License, which allows others to remix, tweak, and build upon the work non-commercially, as long as appropriate credit is given and the new creations are licensed under the identical terms.

For reprints contact: reprints@medknow.com

How to cite this article: Khadri FA, Gopinath VK, Hector MP, Davenport ES. Impact of demographic factors, obesity, and oral health status on self-esteem among school-going children in United Arab Emirates: A cross-sectional study. J Int Soc Prevent Communit Dent 2020;10:329-35. 
lower self-worth among obese individuals. ${ }^{[10-12]}$ A study, examining the relationship between overweight and social acceptance among high school adolescents, with sample size of 17,557 adolescents confirmed that social isolation was seen among overweight adolescents. ${ }^{[18]}$

Some studies report an positive association between obesity and self-esteem, ${ }^{[7,10-13]}$ whereas in others no association was observed between body mass index (BMI) and self-esteem. ${ }^{[20]}$ These variations in the results could be due to difference in the sociodemographic characteristics such as age, race, and gender. In a study conducted by Huang et al., ${ }^{[21]}$ a link was found between sociodemographic characteristics, obesity, and self-esteem. While considering variables such as child's age and race, it should be noted that preschool children are less concerned of their body image compared to early adolescence; ${ }^{[19]}$ and racial attitudes have shown to determine the perception of obesity, as white female adolescents view themselves as more overweight than black female adolescents. ${ }^{[17]}$

Dental caries and periodontal diseases affect general health and well-being, which is manifested as limiting the ability to chew, eat, and communicate. This problem also has an impact on the selfconfidence of the individuals, as they are reluctant to expose their defective teeth when communicating with others. ${ }^{[22]}$ Therefore, there is a need to develop methods to determine how oral disease and disorder have an impact on the daily functioning and the psychosocial aspect of health. ${ }^{[23]}$ The most important part of psychosocial health is self-esteem, which determines the psychological well-being of an individual. Studies have shown that a good appearance and arrangement of teeth in the dental arch will have a positive effect on the self-confidence of children and youngsters. ${ }^{[24,25]}$

Therefore, it is important to evaluate the association of sociodemographic characteristics (age, race, and gender), obesity, and poor oral hygiene with self-esteem in children aged 11-17 years living in United Arab Emirates.

\section{Materials and Methods}

This study was conducted on 803 school children (11-17 years old) from Emirates of Sharjah, UAE. We randomly selected 10 schools (six private and four public) using random digit table to contribute in this randomized cross-sectional study. The private schools were categorized into three categories (low, average, and high) based on the annual tuition fee. Two schools from each were selected by proportional allocation, whereas for the public schools, we selected two boys' and two girls' schools. This research was permitted by
Queen Mary University of London Research Ethics Committee (Reference Number: QMREC2007/60) and was conducted in harmony with the Declaration of Helsinki of 1975, as revised in 2000 given by World Medical Association. The study was conducted with the approval of Ministry of Health and Prevention and Education Department in UAE. Informed consent was given by parents and/or legal guardian, as participants in this research were less than 18 years. The sample size for this study was calculated based on the previously published data, reporting a prevalence of obesity in children of UAE to be $10 \% \cdot{ }^{[26]}$ Significance was set at 0.05 (two-sided) and power at 90\%. A sample size of 650 was considered sufficient to offer a small confidence interval for outcomes measured. However, in view of the nonresponders, a sample of 803 was considered final. The eligibility criteria to participate include healthy children; children with systemic disease or medical condition were excluded.

Oral examination was performed in the school premises using disposable diagnostic kits for each student by the principal investigator (FK) with the child comfortably seated on an arm chair with a back rest. Adequate oral examination was ensured by using an artificial light. Decayed, missing, and filled teeth (DMFT) index according to the World Health Organization (WHO) criteria was used to assess dental caries. ${ }^{[27]}$ Data related to demographic details, oral examination, and toothbrushing habits were recorded and entered into assessment forms. Anthropometric measurements were recorded using a height and weight scale. Obesity was measured by BMI = weight $(\mathrm{kg}) /$ height $\left(\mathrm{m}^{2}\right)$. On the basis of this formula, the children in this study were categorized into normal, overweight, and obese using the International Obesity Task Force (IOTF) cutoff point for children, which is adjusted by age and sex ${ }^{[28]}$ [Table 1].

The mental well-being of 11-17-year-old school-going children was assessed using Rosenberg Self-Esteem Scale. ${ }^{[1]}$ This scale consisted of 10 items to assess an individual's self-esteem, and the overall score is between 0 and 30; there is no discrete cutoff point to indicate high and low, however the higher score value indicates higher self-esteem. The scores given were "strongly disagree" 1 point, "disagree" 2 points, "agree" 3 points, and "strongly agree" 4 points. It should be noted that in this scale, five items have reverse scores (item number: 2 , $5,6,8$, and 9). The scores of all the 10 items were added. Suliman and Halabi ${ }^{[4]}$ carried out the Arabic translation of Rosenberg Self-Esteem Scale and its validation.

Statistical analysis: Data were analyzed using IBM's Statistical Package for the Social Sciences (SPSS) 
software for Windows, version 20.0 (Armonk, New York). Oral hygiene habit, demographic details, prevalence of obesity and dental caries were represented descriptively. The relationship between explanatory variables and their outcomes was assessed by univariate analysis, using simple linear regression for continuous variables and analysis of variance (ANOVA) and $t$ test for categorical variables. The effects of independent variables on dependent variables were assessed by multivariate analysis. Variables were considered as risk factors if they were significant at $5 \%$ level $(P<0.05)$.

\section{Results}

This work evaluated the self-esteem of 11-17-yearold school-going children in Sharjah, UAE. The participation rate among boys and girls was equal in this study; because UAE is a cosmopolitan country, we

Table 1: IOTF cutoffs for overweight and obesity by age and sex corresponding to adult equivalent body mass index of 25 and $30 \mathrm{~kg} / \mathrm{m}^{2}$ for boys and girls

\begin{tabular}{|c|c|c|c|c|}
\hline \multirow[t]{2}{*}{ Age (years) } & \multicolumn{2}{|c|}{ BMI, $25 \mathrm{~kg} / \mathrm{m}^{2}$ (overweight) } & \multicolumn{2}{|c|}{ BMI, $30 \mathrm{~kg} / \mathrm{m}^{2}$ (obese) } \\
\hline & Boys & Girls & Boys & Girls \\
\hline 11 & 20.6 & 20.7 & 25.1 & 25.4 \\
\hline 11.5 & 20.9 & 21.2 & 25.6 & 26.1 \\
\hline 12 & 21.2 & 21.7 & 26.0 & 26.7 \\
\hline 12.5 & 21.6 & 22.1 & 26.4 & 27.2 \\
\hline 13 & 21.9 & 22.6 & 26.8 & 27.8 \\
\hline 13.5 & 22.3 & 23.0 & 27.2 & 28.2 \\
\hline 14 & 22.6 & 23.3 & 27.6 & 28.6 \\
\hline 14.5 & 23.0 & 23.7 & 28.0 & 28.9 \\
\hline 15 & 23.3 & 23.9 & 28.3 & 29.1 \\
\hline 15.5 & 23.6 & 24.2 & 28.6 & 29.3 \\
\hline 16 & 23.9 & 24.4 & 28.9 & 29.4 \\
\hline 16.5 & 24.2 & 24.5 & 29.1 & 29.6 \\
\hline 17 & 24.5 & 24.7 & 29.4 & 29.7 \\
\hline
\end{tabular}

\begin{tabular}{|c|c|c|c|}
\hline & & & \\
\hline variabies & Child & Father & Mother \\
\hline Age (mean SD) & $12.8(1.4)$ & $44.69(6)$ & $38.92(5.2)$ \\
\hline \multicolumn{4}{|l|}{ Age in years (number, \%) } \\
\hline $10-11$ & $163(20.30)$ & & \\
\hline $12-13$ & $392(48.82$ & & \\
\hline $14-15$ & $222(27.64)$ & & \\
\hline $16-17$ & $26(3.24)$ & & \\
\hline \multicolumn{4}{|l|}{ Gender (number, \%) } \\
\hline Boys & $406(50.5)$ & & \\
\hline Girls & $397(49.4)$ & & \\
\hline \multicolumn{4}{|l|}{ Nationality (number, \%) } \\
\hline UAE and other Arab nationals & $603(75)$ & & \\
\hline Indians and other nationals & $200(25)$ & & \\
\hline \multicolumn{4}{|l|}{ School type (number, \%) } \\
\hline Public & $269(33.5)$ & & \\
\hline Private & $534(66.5)$ & & \\
\hline \multicolumn{4}{|l|}{ Parents education } \\
\hline No education & & $24(3)$ & $34(4)$ \\
\hline School education & & $329(41)$ & $404(50.3)$ \\
\hline College/university & & $426(55)$ & $360(45)$ \\
\hline \multicolumn{4}{|l|}{ Parents occupation } \\
\hline Employed & & 733 (91.17) & $197(24.53)$ \\
\hline Unemployed/housewife & & $46(5.7)$ & $601(74.8)$ \\
\hline Deceased & & $24(3)$ & $5(0.6)$ \\
\hline \multicolumn{4}{|l|}{ Family income } \\
\hline Less than 7000 Aed & & & \\
\hline More than 7000 Aed & & & \\
\hline
\end{tabular}


have placed them in different category based on their ethnic origin, attending both public and private school [Table 2].

Self-esteem scores in relation to three weight groups are shown in Table 3. Rosenberg scores of the individual's self-esteem was the lowest among obese followed by overweight when compared to normal weight children $(P=0.095)$. The mean Rosenberg Self-esteem Scale score between participants with dental caries (19.87, standard deviation $[\mathrm{SD}], \pm 3.80)$ and caries free $(19.49$, $\mathrm{SD}, \pm 3.87)$ revealed no statistically significant difference $(P=0.199)$.

Assessment of oral hygiene indicated that $93 \%$ of the children in this study brushed their teeth daily, although brushing frequency was significantly higher in females $(98 \%)$ when compared to males $(89 \%)(P<0.001)$ [Table 4]. It was noticed that children with higher selfesteem scores of $19.8(\mathrm{SD}, \pm 3.85)$ brushed their teeth more often $(P=0.006)$.

While correlating the Rosenberg Self-esteem Scale scores with demographic characteristics, it was observed that the scores were different in different age-groups and nationalities; the mean score values were lower in young children and Indian nationals $(P<0.001)$. However, other variables such as child's gender and school type were not significant. There was a negative relationship among the self-esteem score with BMI, when BMI was treated as a continuous variable [Table 5].
In the final multivariate regression model [Table 6], a correlation was observed among age and self-esteem, as older children were with higher scores $(P=0.001)$. BMI had negative association $(P=0.006)$, and self-esteem score values of Indian children were significantly lower $(P=0.004)$.

\section{Discussion}

This work evaluated if self-esteem in 11-17-year-old school-going children differs in relation to the dental health (DMFT and toothbrushing habits), obesity/ overweight (BMI) status, and demographic factors such as age, gender, and race using Rosenberg Self-esteem Scale. ${ }^{[1]}$ This self-esteem scale has been previously validated among Canadian high school population. ${ }^{[29]}$ In our study, levels of self-esteem were associated with age, as younger children had lower score values compared with older children. This finding is expected as psychological and cognitive development takes place during this period. ${ }^{[10]}$ Children in the early adolescence are concerned about their body image, ${ }^{[19,30]}$ therefore being overweight and obese could have an adverse psychological effect in the young child's mind. Previous studies have shown similar results. ${ }^{[10,31]}$

While evaluating the relationship of the 11-17-year-old children's self-esteem with their ethnic background, in was noted that children belonging to Indian ethnicity had lower score values when compared with Emirati, nonlocal Arab, and other nationalities. This finding is

\begin{tabular}{lccc}
\hline & Table 3: Rosenberg self-esteem by weight groups & & \\
\hline Weight group & Mean (SD) & $(19.67,20.30)$ & ANOVA, $P$ vallue \\
\hline Normal weight & $19.98(3.53)$ & $(18.90,20.10)$ & \\
Overweight & $19.50(4.18)$ & $(18.46,20.03)$ & \\
Obese & $19.25(3.82)$ & & \\
\hline SD
\end{tabular}

$\mathrm{SD}=$ standard deviation, $\mathrm{CI}=$ confidence interval, $\mathrm{ANOVA}=$ analysis of variance

Table 4: Oral hygiene habits by gender

\begin{tabular}{|c|c|c|c|}
\hline \multirow[t]{2}{*}{ Oral hygiene } & \multicolumn{2}{|c|}{ Gender } & \multirow[t]{2}{*}{$P$ value } \\
\hline & Male, $N(\%)$ & Female, $N(\%)$ & \\
\hline \multicolumn{4}{|l|}{ Toothbrushing } \\
\hline Yes & $363(89.4 \%)$ & $387(97.5 \%)$ & \\
\hline No & $43(10.6 \%)$ & $10(2.5 \%)$ & $<0.001$ \\
\hline \multicolumn{4}{|l|}{ Brushing frequency } \\
\hline None & $34(8.4 \%)$ & $6(1.5 \%)$ & $<0.001$ \\
\hline Once & $118(29.1 \%)$ & $77(19.4 \%)$ & \\
\hline Twice & $198(48.8 \%)$ & $236(59.4 \%)$ & \\
\hline Three times & $56(13.8 \%)$ & $78(19.6 \%)$ & \\
\hline \multicolumn{4}{|l|}{ Brushing time } \\
\hline None & $32(7.9 \%)$ & $6(1.5 \%)$ & $<0.001$ \\
\hline Morning & $85(20.9 \%)$ & $72(18.1 \%)$ & \\
\hline Evening & $45(11.1 \%)$ & $12(29.2 \%)$ & \\
\hline Morning and evening & $244(60.1 \%)$ & $305(76.8 \%)$ & \\
\hline
\end{tabular}




\begin{tabular}{|c|c|c|c|}
\hline & & \multicolumn{2}{|c|}{ Table 5: Association between Rosenberg Self-Esteem Scale scores and sociodemographic variables } \\
\hline Variables & Mean (SD) & ANOVA, $P$ value & Regression, $P$ value \\
\hline \multicolumn{4}{|l|}{ Age } \\
\hline 10 & $19.1(2.3)$ & 0.004 & 0.003 \\
\hline 11 & $19.5(3.7)$ & & \\
\hline 12 & $18.8(3.5)$ & & \\
\hline 13 & $20.2(4)$ & & \\
\hline 14 & $20.1(4)$ & & \\
\hline 15 & $21(3.7)$ & & \\
\hline 16 & $19.6(3.7)$ & & \\
\hline 17 & $20.5(0.84)$ & & \\
\hline \multicolumn{4}{|l|}{ Gender } \\
\hline Male & $19.8(3.8)$ & & \\
\hline Female & $19.8(3.8)$ & 0.98 & 0.98 \\
\hline \multicolumn{4}{|l|}{ Nationality } \\
\hline Emirati & $19.8(3.9)$ & & ------- \\
\hline Arabs & $20.1(3.7)$ & 0.01 & \\
\hline Indian & $18.8(3.6)$ & & \\
\hline Others & $20.1(3.7)$ & & \\
\hline \multicolumn{4}{|l|}{ School type } \\
\hline Public & $20(3.9)$ & & \\
\hline Private & $19.6(3.8)$ & 0.197 & 0.197 \\
\hline \multicolumn{4}{|l|}{ Mother's education } \\
\hline None & $21.2(3.4)$ & 0.79 & 0.908 \\
\hline Primary & $19.9(3.8)$ & & \\
\hline Secondary & $19.4(3.4)$ & & \\
\hline High school & $19.7(3.8)$ & & \\
\hline College & $19.9(4)$ & & \\
\hline \multicolumn{4}{|l|}{ Father's education } \\
\hline None & $19.9(2.9)$ & 0.045 & 0.906 \\
\hline Primary & $20.4(3.2)$ & & \\
\hline Secondary & $20(3.9)$ & & \\
\hline High School & $19.1(3.6)$ & & \\
\hline College & $20(3.9)$ & & \\
\hline \multicolumn{4}{|l|}{ Income } \\
\hline 1000-3000 Aed & $19.4(4.0)$ & 0.131 & 0.063 \\
\hline 3000-7000 Aed & $19.4(3.5)$ & & \\
\hline$>7000 \mathrm{Dhs}$ & $20(3.9)$ & & \\
\hline \multicolumn{4}{|l|}{ Weight group } \\
\hline Normal & $20(3.5)$ & 0.095 & 0.032 \\
\hline Overweight & $19.5(4.2)$ & & \\
\hline \multirow[t]{2}{*}{ Obese } & $19.2(3.8)$ & & \\
\hline & Coefficie & & \\
\hline BMI & \multicolumn{2}{|c|}{$-0.055(-0.107,-0.002)$} & 0.041 \\
\hline DMFT & \multicolumn{2}{|c|}{$0.054(-0.035,0.143)$} & 0.232 \\
\hline
\end{tabular}

$\mathrm{SD}=$ standard deviation, ANOVA $=$ analysis of variance, $\mathrm{CI}=$ confidence interval, $\mathrm{BMI}=$ body mass index, $\mathrm{DMFT}=$ decayed, missing, and filled teeth

\begin{tabular}{lccc}
\hline \multicolumn{3}{c}{ Table 6: Final multivariate regression model of Rosenberg Self-Esteem Scale scores and explanatory variables } \\
\hline Predictors & Odds ratio & $95 \%$ Confidence interval & $P$ value \\
\hline BMI & -0.077 & $-0.133,-0.022$ & 0.006 \\
Indian subcontinent & -1.097 & $-1.845,-0.348$ & 0.004 \\
School type & 0.165 & $-0.471,0.801$ & 0.610 \\
Age & 0.336 & $0.129,0.543$ & 0.001 \\
Mother's education & 0.103 & $-0.211,0.418$ & 0.518 \\
Income & 0.324 & $-0.109,0.757$ & 0.142 \\
DMFT & 0.011 & $-0.083,0.105$ & 0.813 \\
Father's education & -0.047 & $-0.386,0.293$ & 0.787 \\
\hline
\end{tabular}

BMI = body mass index, DMFT $=$ decayed, missing, and filled teeth 
in correlation with the studies conducted by Strauss ${ }^{[10]}$ and Fallon et al. ${ }^{[17]}$ reporting the effect of race on the psychological well-being of the individual. It should also be noted that in some ethnic groups, obesity is not considered a problem, for example Hispanic men and women are not concerned about being overweight or obese when compared to the white people living in the same location. ${ }^{[32]}$ Therefore, the understanding is that each ethnic group has their perception about being overweight and obese, which in turn had an effect on their self-esteem. The reasons for low selfesteem among Indian children living in UAE needs further clarification, as it can be noted that in these children, BMI was lower when compared to other nationality children. Hence, these low levels of selfesteem in Indian children need further investigation as it might not be linked with the child's self-perception of their body shape. Although obese children had a lower self-esteem in our study, there was no significant difference between the groups studied. This could be due to the influence of ethnic and cultural values in the society.

We attempted to link the prevalence of dental caries in 11-17-year-old children with their self-esteem. Although prevalence of dental caries was high in boys and children in public schools, the mean DMFT score values were not significantly associated with their selfesteem scores. There are not many studies that looked into this aspect of relating Rosenberg Self-esteem Scale scores with dental caries status. Most studies related aesthetics of teeth to mental well-being. ${ }^{[2,25]}$ But in one recently conducted study, 2014 children in the age-group of $12-15$ years were examined to find the relationship between oral health status, academic achievements, and self-esteem. Nevertheless, no significant correlation was reported between the children's self-esteem and DMFT scores, ${ }^{[33]}$ which is in correlation with our results.

As evidence indicates that obesity increases the rate of periodontal disease onset owing to the increased production of reactive oxygen species by macrophages in obese individuals, ${ }^{[34]}$ therefore, meticulous evaluation of oral and periodontal health of obese patients and its relationship to the self-esteem is needed..$^{[9,23,35]}$ Presently, the majority of children brushed their teeth, although the percentage of females brushing their teeth was significantly higher. In correlation with these findings, a study conducted in UAE also showed similar toothbrushing behavior among children. ${ }^{[36]}$ While evaluating self-esteem with oral hygiene practices, it was observed that 11-17-year-old school-going children with high self-esteem brushed their teeth often when compared to children with lower self-esteem. Similar observation was seen in studies conducted by Macgregor and Balding ${ }^{[9]}$ and Regis et al. ${ }^{[8]}$

\section{Conclusion}

This study confirmed that the child's obesity and dental caries status had no significant influence on their selfesteem. However, high self-esteem in older school children is associated with increased tooth brushing frequently, indicating the link between self-esteem and an individual's oral health awareness. Rosenberg Selfesteem Scale scores were lower in young children and Indian school-going children living in UAE.

\section{Acknowledgements}

None.

FINANCIAL SUPPORT AND SPONSORSHIP

Nil.

CONFLICTS OF INTEREST

There are no conflicts of interest.

\section{Author CONTRIBUtions}

All authors contributed in designing the study, FAK and VKG contributed in data collection; FAK, ESD, $\mathrm{MPH}$, and VKG contributed in data analysis and interpretation; VKG and FAK drafted the manuscript. All authors read and approved the final manuscript, and the requirements for authorship as stated earlier in this document have been met, and that each author believes that the manuscript represents honest work, and that the information is not provided in another form.

\section{ETHICAL POLICY AND INSTITUTIONAL REVIEW BOARD STATEMENT}

This research was permitted by Queen Mary University of London Research Ethics Committee (Reference Number: QMREC2007/60) and was conducted in harmony with the Declaration of Helsinki of 1975, as revised in 2000 given by World Medical Association. Approval was procured from the Ministry of Health and Prevention and Education Department in UAE to conduct the study.

\section{Declaration of PATIENT CONSENT}

The authors certify that they have obtained all appropriate patient consent forms. In the form the patient(s) has/have given his/her/their consent for his/ her/their images and other clinical information to be reported in the journal. The patients understand that their names and initials will not be published and due efforts will be made to conceal their identity, but anonymity cannot be guaranteed. 


\section{DATA AVAILABILITY STATEMENT}

Data set used in this study is available within the article.

\section{REFERENCES}

1. Rosenberg M. Rosenberg Self-esteem Scale (RSE). Acceptance and Commitment Therapy Measures package. 1965;61:52.

2. Shapurian R, Hojat M, Nayerahmadi H. Psychometric characteristics and dimensionality of a Persian version of Rosenberg self-esteem scale. Percept Mot Skills 1987;65:27-34.

3. Martín-Albo J, Núñiez JL, Navarro JG, Grijalvo F. The Rosenberg self-esteem scale: Translation and validation in university students. Span J Psychol 2007;10:458-67.

4. Suliman WA, Halabi J. Critical thinking, self-esteem, and state anxiety of nursing students. Nurse Educ Today 2007;27:162-8.

5. Kawabata T, Cross D, Nishioka N, Shimai S. Relationship between self-esteem and smoking behavior among Japanese early adolescents: Initial results from a three-year study. J Sch Health 1999;69:280-4.

6. Schmalz DL, Deane GD, Birch LL, Davison KK. A longitudinal assessment of the links between physical activity and self-esteem in early adolescent non-hispanic females. $\mathbf{J}$ Adolesc Health 2007;41:559-65.

7. Kristjansson AL, Sigfusdottir ID, Allegrante JP. Health behavior and academic achievement among adolescents: The relative contribution of dietary habits, physical activity, body mass index, and self-esteem. Health Educ Bhav 2010;37:51-64.

8. Regis D, Macgregor ID, Balding JW. Differential prediction of dental health behaviour by self-esteem and health locus of control in young adolescents. J Clin Periodontol 1994;21:7-12.

9. Macgregor ID, Balding JW. Self-esteem as a predictor of toothbrushing behaviour in young adolescents. J Clin Periodontol 1991;18:312-16.

10. Strauss RS. Childhood obesity and self-esteem. Pediatrics 2000; 105:e15.

11. Franklin J, Denyer G, Steinbeck KS, Caterson ID, Hill AJ. Obesity and risk of low self-esteem: A statewide survey of Australian children. Pediatrics 2006;118:2481-7.

12. French SA, Story M, Perry CL. Self-esteem and obesity in children and adolescents: A literature review. Obes Res 1995;3:479-90.

13. Stern M, Mazzeo SE, Gerke CK, Porter JS, Bean MK, Laver JH. Gender, ethnicity, psychosocial factors, and quality of life among severely overweight, treatment-seeking adolescents. J Pediatr Psychol 2007;32:90-4.

14. Sahoo K, Sahoo B, Choudhury AK, Sofi NY, Kumar R, Bhadoria AS. Childhood obesity: Causes and consequences. J Family Med Prim Care 2015;4:187-92.

15. Swallen KC, Reither EN, Haas SA, Meier AM. Overweight, obesity, and health-related quality of life among adolescents: The national longitudinal study of adolescent health. Pediatrics 2005;115:340-7.

16. Korczak DJ, Lipman E, Morrison K, Szatmari P. Are children and adolescents with psychiatric illness at risk for increased future body weight? A systematic review. Dev Med Child Neurol 2013;55:980-7.

17. Fallon EM, Tanofsky-Kraff M, Norman AC, McDuffie JR, Taylor ED, Cohen ML, et al. Health-related quality of life in overweight and nonoverweight black and white adolescents. J Pediatr 2005;147:443-50.

18. Strauss RS, Pollack HA. Social marginalization of overweight children. Arch Pediatr Adolesc Med 2003;157:746-52.

19. Skemp-arlt KM, Rees KS, Mikat RP, Seebach EE. Body image dissatisfaction among third, fourth, and fifth grade children. California J Health Promotion 2006;4:58-67.

20. Ozmen D, Ozmen E, Ergin D, Cetinkaya AC, Sen N, Dundar PE, et al. The association of self-esteem, depression and body satisfaction with obesity among Turkish adolescents. BMC Public Health 2007;7:80.

21. Huang JS, Norman GJ, Zabinski MF, Calfas K, Patrick K. Body image and self-esteem among adolescents undergoing an intervention targeting dietary and physical activity behaviors. J Adolesc Health 2007;40:245-51.

22. Naito M, Yuasa H, Nomura Y, Nakayama T, Hamajima N, Hanada N. Oral health status and health-related quality of life: A systematic review. J Oral Sci 2006;48:1-7.

23. Locker D, Clarke M, Payne B. Self-perceived oral health status, psychological well-being, and life satisfaction in an older adult population. J Dent Res 2000;79:970-5.

24. Bryan RA, Welbury RR. Treatment of aesthetic problems in paediatric dentistry. Dent Update 2003;30:307-13.

25. Bryan RA, Welbury RR. Treatment of aesthetic problems in paediatric dentistry. SADJ 2006;61:160, 162, 164-5.

26. Malik M, Bakir A. Prevalence of overweight and obesity among children in the United Arab Emirates. Obes Rev 2007;8:15-20.

27. WHO. Oral Health Survey. Basic Methods. 4th ed. Geneva, Switzerland: World Health Organization; 1997.

28. Cole TJ, Bellizzi MC, Flegal KM, Dietz WH. Establishing a standard definition for child overweight and obesity worldwide: International survey. BMJ 2000;320:1240-3.

29. Bagely C, Bolitho F, Bertrand L. Norms and construct validity of the Rosenberg Self-esteem Scale in Canadian high school populations: Implications for counselling. Can J Couns 1997;31:82-92.

30. Mikkilä V, Lahti-Koski M, Pietinen P, Virtanen SM, Rimpelä M. Associates of obesity and weight dissatisfaction among Finnish adolescents. Public Health Nutr 2003;6:49-56.

31. Erol RY, Orth U. Self-esteem development from age 14 to 30 years: A longitudinal study. J Pers Soc Psychol 2011;101:607-19.

32. Stern MP, Pugh JA, Gaskill SP, Hazuda HP. Knowledge, attitudes, and behavior related to obesity and dieting in Mexican Americans and Anglos: The San Antonio Heart Study. Am J Epidemiol 1982;115:917-28.

33. Gopalan T, Asokan S, John JB, Geetha Priya PR. School absenteeism, academic performance, and self-esteem as proxy measures of oral health status: A cross-sectional study. J Indian Soc Pedod Prev Dent 2018;36:339-46.

34. Patini R, Gallenzi P, Spagnuolo G, Cordaro M, Cantiani M, Amalfitano A, et al. Correlation between metabolic syndrome, periodontitis and reactive oxygen species production. A pilot study. Open Dent J 2017;11:621-7.

35. Miguel JA, Palomares NB, Feu D. Life-quality of orthognathic surgery patients: The search for an integral diagnosis. Dental Press J Orthod 2014;19:123-37.

36. Gopinath VK, Rahman B, Awad MA. Assessment of gingival health among school children in Sharjah, United Arab Emirates. Eur J Dent 2015;9:36-40. 